NBER WORKING PAPER SERIES

\title{
WHEN DO CENTRAL BANK INTERVENTIONS INFLUENCE INTRA-DAILY AND LONGER-TERM EXCHANGE RATE MOVEMENTS?
}

\author{
Kathryn M. E. Dominguez \\ Working Paper 9875 \\ http://www.nber.org/papers/w9875 \\ NATIONAL BUREAU OF ECONOMIC RESEARCH \\ 1050 Massachusetts Avenue \\ Cambridge, MA 02138 \\ July 2003
}

I am grateful to Chang-ching Lin for outstanding research assistance, Olsen and Associates for providing the FXFX intradaily indicative quotes and the Reuters news tape, Tim Bollerslev and Michael Melvin for sharing their flexible fourier form regression programs and Alain Chaboud and Steve Weinberg for providing the daily integrated volatility series. I thank Philippe Bacchetta, Paul DeGrauwe, Charles Goodhart, Rich Lyons, Richard Olsen, Carol Osler, Mark Taylor and Jonathan Wright for helpful comments and suggestions. The views expressed herein are those of the author and not necessarily those of the National Bureau of Economic Research

(C)2003 by Kathryn M. E. Dominguez. All rights reserved. Short sections of text, not to exceed two paragraphs, may be quoted without explicit permission provided that full credit, including $(\mathbb{C}$ notice, is given to the source. 
When Do Central Bank Interventions Influence Intra-Daily and Longer-Term Exchange Rate Movements?

Kathryn M. E. Dominguez

NBER Working Paper No. 9875

July 2003

JEL No. F31, G14, G15, E58

\begin{abstract}
This paper examines dollar interventions by the G3 governments since 1989, and the reasons that trader reactions to these interventions might differ over time and across central banks. Market microstructure theory provides a framework for understanding the process by which sterilized central bank interventions are observed and interpreted by traders, and how this process, in turn, might influence exchange rates. Using intra-daily and daily exchange rate and intervention data, the paper analyzes the influence of interventions on exchange rate volatility, finding evidence of both within day and daily impact effects, but little evidence that interventions increase longer-term volatility.

Kathryn M. E. Dominguez

Gerald R. Ford School of Public Policy

University of Michigan

Lorch Hall

611 Tappan Street

Ann Arbor, MI 48109

and NBER

kathrynd@umich.edu
\end{abstract}




\section{Introduction}

On May 31, 1995 the U.S. government purchased a total of \$500 million against marks and $\$ 500$ million against yen on three occasions between the hours of 1:45pm and 2:26pm (Eastern Standard Time), resulting in a $2 \%$ increase in the value of the dollar against both the mark and yen over the course of the day. ${ }^{1}$ On other occasions when the U.S. government intervened in the dollar exchange rate market, however, the dollar either moved in the opposite direction to that expected, or did not move at all. This paper examines dollar interventions by the G3 governments since 1989, and the reasons that market reactions to these interve ntions might differ over time and across central banks.

Standard models of exchange rate determination identify at least two channels through which interventions might be expected to influence exchange rates: the portfolio balance channel and the signaling channel. However, neither of these channels is easily reconciled with the empirical evidence, which suggests that sometimes intervention works and sometimes it does not. Of course, standard exchange rate determination models have a difficult time explaining (often the lack of) exchange rate reactions to all kinds of purportedly fundamental information, suggesting that it may be worth reexamining standard models before drawing conclusions regarding the efficacy of intervention.

One approach to exchange rate modeling that has gone some distance toward reconciling observed short- term currency movements and economic theory is the market microstructure approach. In the context of intervention, market microstructure provides a

\footnotetext{
${ }^{1}$ During New York trading hours on May 31, 1995 the dem-usd rate opened at 1.385 and closed at 1.4135 and the yen-usd rate opened at 82.70 and closed at 84.40. The Bundesbank and the BOJ coordinated their interventions with the Fed on this day. Reuters reports indicate that the Bundesbank purchased $\$ 395.6$ million against the mark on two occasions (starting just before the Fed was in the market), and the BOJ purchased \$767.4 million against yen on one occasion (just before the last Fed operation).
} 
framework for understanding the process by which central bank interventions are observed and interpreted by traders, and how this process, in turn, might result in exchange rate changes. Even if interventions are informative, for example if they reveal information that is considered pric e relevant, exchange rates might not react immediately if traders learn about interventions at different times. Likewise, if interventions are largely non-informative (and are simply a central bank's attempt to target exchange rates away from fundamentals), interventions might still impact prices and volatility in the very short-run if traders misinterpret the (lack of) information content of the interventions.

Recent advances in market microstructure theory, new sources of data on exchange rates and central bank interventions, and in particular, the availability of high frequency data, offer new tools with which to shed light on the old question of when central bank interventions are likely to influence exchange rates. ${ }^{2}$ Section II offers a simple version of a market microstructure model and introduces a role for intervention. Section III describes the G3 intervention and exchange rate data. Section IV provides an empirical examination of the intra-day and daily dynamics of interventions and exchange rate volatility. Section 5 is the conclusion.

\section{Market Microstructure and Intervention}

The exchange rate microstructure model developed by Bacchetta and van Wincoop (2003) provides a way to think about why trader heterogeneity (based on differences in information or the interpretation of information) might lead to short-run price

\footnotetext{
${ }^{2}$ See Dominguez and Frankel (1993ab) and Humpage (1999). Sarno and Taylor (2001) and Edison (1993) provide excellent surveys of the intervention literature. Also, see Dominguez (2003b), Ito (2002), De Grauwe and Grimaldi (2003) and Taylor (2003) for recent contributions.
} 
and volatility effects in reaction to information revelation. ${ }^{3}$ Interventions can easily be included in the model with the potential to provide price-relevant information. In this model, both information-based trades and non-informative trades can move exchange rates in the short run depending on aggregate market ability to differentiate noise from fundamentals. The model assumes that longer-term exchange rate behavior is well explained by fundamentals.

Consider a standard asset pricing model of exchange rates in which the current exchange rate, $e_{t}$, is the discounted present value of expected macro fundamental differentials, $M_{t+k}$, and a risk premium, $r p_{t+k}$, associated with non-fundamentals trade. ${ }^{4}$ Assume traders have higher order expectations, $\overline{E_{t}^{k}}$ (such that the exchange rate at time $\mathrm{t}$ depends on the fundamental at time $t$, and the average expectation of the fundamental in all future periods, as a consequence of which the expectation of other investors' expectations matters). Exchange rates may then be expressed as:

$$
e_{t}=\frac{1}{1+\beta} \sum_{k=0}^{\infty}\left(\frac{\beta}{1+\beta}\right)^{k} \bar{E}_{t}^{k}\left(M_{t+k}-r p_{t+k}\right) \text {, }
$$

where $\beta$ can be interpreted as the interest semi-elasticity of money demand. If market participants receive information (or signals) at time $\mathrm{t}$ about future fundamentals, $M_{t+k}$, but this information is not common knowledge (either because people receive difference bits of information or because they interpret the information differently), then there is a common average signal among traders (assuming there are large numbers of market

\footnotetext{
${ }^{3}$ See Lyons (2001) for a thorough discussion of market microstructure in foreign exchange markets as well as Evans and Lyons (2002ab). For a more general treatment of market microstructure see O'Hara (1995).

${ }^{4}$ In Bacchetta and van Wincoop (2003) the risk premium arises because some proportion of investors have a noisy expected excess return on foreign bonds and the net supply of foreign bonds resulting from the expectational error is non-observable (so that the irrational agents do not know their expectational error).
} 
participants) but heterogeneity across individuals (and traders will expect their own expectation next period to differ from that of others). Bacchetta and van Wincoop (2003) show that this sort of information heterogeneity leads both to magnification and to endogenous persistence of the impact of non-fundamentals trade on the exchange rate. Government exchange market interventions in this kind of setting may provide information to market participants that allows them to distinguish more accurately between fundamental and non-fundamental information. Define an intervention operation known to individual $\mathrm{i}$ at time $\mathrm{t}, I_{t}^{i}$, as providing information about future fundamentals with probability $\rho_{t}^{i}$, and providing non-fundamentals information with probability $\left(1-\rho_{t}^{i}\right)$ :

$$
I_{t}^{i}=\rho_{t}^{i}\left(M_{t+k}\right)+\left(1-\rho_{t}^{i}\right)\left(r p_{t+k}\right)+\eta_{t}^{i}
$$

where $\sum \eta_{t}^{i}$ is the error term that goes to zero if interventions are common knowledge. If the value of $\rho_{t}^{i}$ is only learned over time, then intervention operations will in the shortrun (before $\rho$ is known) potentially add to the weight of non-fundamentals driven exchange rate movements

The model implies that, if interventions are "informative" $\left(\sum \rho_{t}^{i}=1\right)$ and are common knowledge $\left(\sum \eta_{t}^{i}=0\right)$, then they should help reduce the rational confusion (between fundamental and non-fundamental induced exchange rate movements) that arises in the Bacchetta and van Wincoop (2003) model. Likewise, if interventions are not common knowledge $\left(\sum \eta_{t}^{i} \neq 0\right)$, or if interventions are uninformative $\left(\sum \rho_{t}^{i}<1\right)$, then interventions will increase short-term non-fundamentals induced exchange rate movements. Over time interventions should become common knowledge and the market 
will learn the value of $\rho$. Therefore, only those interventions that are informative should be expected to have long-term effects on exchange rates. This suggests that the very short-run influence of interventions may differ from its longer run effects.

Previous empirical tests of how microstructure issues might influence the relationship between intervention and exchange rates include Beattie and Fillion (1999), Cai, Cheung, Lee and Melvin (2001), Chang and Taylor (1998), Dominguez (2003a), Evans and Lyons (2001), Fischer and Zurlinden (1999), Goodhart and Hesse (1993), Neely (2002), Pasquariello (2001, 2002), Payne and Vitale (forthcoming) and Peiers (1997). Each of these studies focuses on the effects of different central banks over different sample periods, often using different data sets, making cross study comparisons difficult. As a general matter, and in contrast to papers that study the longer-term effects of sterilized central bank interventions, studies examining intra-daily effect of intervention find strong evidence of impact effects. ${ }^{5}$

LeBaron's (1999) finding that intervention days are the source of unusual profits for traders using technical analysis is noteworthy in this context. He finds that simple moving average trading rule profits are significant in daily forex data if intervention days are included in the sample -- when interventions are excluded, profits go to zero. Using more finely timed data, Neely (2002) however, finds that interventions are unlikely to have "caused" the increase in trading rule profits, but instead that interventions tend to arise

\footnotetext{
${ }^{5}$ For example, Peiers (1997) examines how interactions between informed (defined to be indications provided by Deutsche Bank (DB)) and uninformed foreign exchange traders (indications given by all other banks) give rise to short-term price leadership during periods of central bank intervention. She finds that, during the period October 1992 to September 1993, volatility increases five minutes prior to Bundesbank interventions, and that there is evidence of DB price leadership from 60 to 25 minutes prior to Reuters reports.
} 
during periods when exchange rates are trending in a manner that would likely lead to technical trading rule profits.

\section{G3 Intervention and Exchange Rate Data}

The intra-daily exchange rate data used in this paper are the Reuter's FXFX series tick-by-tick indicative quotes on Fed intervention days as well as a control sample of 25 days with no interventions. ${ }^{6}$ A limitation of the FXFX data is that because they are quotes and not transactions they do not provide volume information, so it is not possible to examine the joint dynamics of volume (or order flow) and price. ${ }^{7}$ Another disadvantage of the data set is that, because it includes only intervention days, it is not possible to measure persistent effects of interventions.

The FXFX data used in the paper cover 69 days over the period August 1989 to August 1995 when the Fed intervened in the dem- usd market, and 66 days when the Fed intervened in the yen-usd market. ${ }^{8}$ The propensity to intervene on a given day varied across the sample period. The U.S, Japanese and German governments all intervened actively in the early part of the sample, while only the Bank of Japan (BOJ) continued to actively interve ne after 1992. Figures 1 and 2 show daily U.S. dollar intervention

\footnotetext{
${ }^{6}$ The data are collected by Olsen and Associates (Research Institute for Applied Economics, Zurich Switzerland) using O\&A proprietary real-time data collection software and are filtered as recommended by Dacorogna et al. (1993). The control dates were selected to provide a representative sample of nonintervention days over the period when the intervention operations take place. These data are used to create the volatility seasonal used in the empirical tests to follow.

${ }^{7}$ Goodhart et al. (1996) and Danielsson and Payne (2002) find that the basic characteristics of 5-minute FXFX returns closely match those calculated for transactions prices but find that quote frequency and bidask spreads in the FXFX data are not good proxies to transaction volume or spreads.

${ }^{8}$ Two additional Fed intervention operations have occurred since August 1995. On June 17, 1998 the Fed sold $\$ 833$ million against the yen in cooperation with the BOJ and on September 22, 2000 the Fed purchased a total of 1.5 billion euros against the dollar in cooperation with the ECB, the BOJ, the Bank of Canada and the Bank of England.
} 
operations in the mark and yen markets along with the corresponding bilateral exchange rates over the sample period. ${ }^{9}$

The G3 central banks release historical daily intervention data. Unfortunately, they do not provide the exact timing of interventions, nor do they disclose how many operations occurred over the course of the day. ${ }^{10}$ The only available source of timing information for G3 interventions comes from Reuters reports of interventions (which is also the most likely source of information for those traders in the market that are not directly involved in the intervention transaction).

The Reuters news reports used in this study are from the Reuters AAMM Page News (Money Market Headline News). Along with reports of central bank intervention, the Reuters data include announcements of various macroeconomic statistics, statements by central bank and government officials and reports of major economic events. In order to control for the impact of other news on exchange rates, these Reuters news reports are also included in the empirical work. In particular, dummy variables indicate the timing of all major macroeconomic announcements and statements regarding exchange rate policy by officials of the G-3 central banks on the intervention sample days. Table 1 lists each of the dummy variables created from the Reuters reports and the day-of-week and average time (GMT) when the announcements are made.

\footnotetext{
${ }^{9}$ In the United States the U.S. Treasury and the Federal Reserve have independent legal authority to intervene in foreign exchange markets. In practice, the U.S. Treasury and the Fed typically act jointly and split the costs of intervention equally against their separate accounts. The New York Fed implements intervention policy for the United States and for this reason I follow the convention of associating U.S. intervention operations with the Fed in the paper. Similarly, in Japan intervention decisions are made by the Ministry of Finance and implemented by the Bank of Japan (BOJ). The Bundesbank had sole jurisdiction over German intervention decisions and implemented intervention operations prior to 1999. ${ }^{10}$ The Swiss National Bank is an exception. The SNB provides exact timing and transaction prices for interventions (see Fischer and Zurlinden (1999), Payne and Vitale (forthcoming) and Pasquarliello (2001) for studies using these data).
} 
The Reuters reports indicate that central banks typically intervene during business hours in their respective markets. ${ }^{11}$ Frequency distributions of the times of G3 intervention suggest that the BOJ is most likely to intervene at 3:56:36 GMT (or around 1pm in Tokyo). The Bundesbank is most likely to intervene at 11:31:16 GMT (or at 12:30pm in Frankfurt). And, the Fed is most likely to intervene at 14:57:10 GMT (or 10am EST). Table 2 shows the relative timing of the Tokyo, Frankfurt and New York markets using the GMT scale and indicates the times when Reuters reports that each central bank is most likely to be in the market. It is worth noting that Tokyo business hours end just as the Frankfurt market opens and the New York market overlaps the Frankfurt market for two hours. The New York market closes two hours before the Tokyo financial market opens.

Getting the timing of interventions right is critical to measuring the short-term influence of interventions on foreign exchange markets. Evidence in Andersen, Bollerslev, Diebold and Vega (2003) and Almeida, Goodhart and Payne (1998) suggests that conditional mean adjustments of exchange rates to macro news occur quickly (though they also find that conditional variance adjustments are more gradual). Tables 3 and 4 provide descriptive information about the central bank interventions that are examined in the next section. The Fed intervened on 268 occasions over 104 days (in either the dem-usd or yen-usd markets) over the sample period August 1989 through August 1995. Many of the Fed's intra-daily interventions were clustered in the same hour of the day. Most Fed interventions occurred during the overlap in New York and European trading hours. And $31 \%$ of Fed interventions were coordinated with the

\footnotetext{
${ }^{11}$ Neely (2000) provides detailed information about the practice of central bank intervention based on survey data.
} 
Bundesbank in the dem- usd market, while $54 \%$ were coordinated with the BOJ in the yen-usd market. ${ }^{12}$

Before formally testing for a relationship between exchange rates, intervention and macro announcements, it is interesting to examine the 25 largest returns over the sample period together with the Reuters time-stamped events that surround these unusually large returns. Tables 4 and 5 present this information for dem- usd and yen- usd returns, respectively. The timing of large returns and the timing of macro announcements tends to be very closely aligned. For example, many of the large returns are timed within 10 seconds of a (scheduled) macroeconomic announcement. In contrast, some of the large returns are only loosely synchronized with interventions. The Reuters time-stamp typically lags the large returns, sometimes by as much as two hours. Of course, it is possible that the "cause" of the large return is unrelated to any news event reported by Reuters.

IV. Measuring the Intra-daily influences of central bank interventions A fundamental property of high frequency data is that observations can occur at varying time intervals resulting in irregular spacing of quotes. Standard econometric techniques require regularly spaced data. The approach to irregularly spaced data used in this paper is to create from these data a regularly spaced time series over a discrete time interval. Defining the tick-by-tick price $(\mathrm{P})$ as the average of the bid and ask:

$$
P_{t, h} \equiv \frac{\left[\log P_{t, h}^{a s k}+\log P_{t, h}^{b i d}\right]}{2}
$$

\footnotetext{
${ }^{12}$ In the intra-day context a "coordinated" Fed intervention is defined as an intervention that occurs within 2 hours of a BOJ or Bundesbank intervention.
} 
where $t, h$ is the sequence of tick recording times which is irregularly spaced, then the regular-space price is defined as:

$$
P_{t, n} \equiv \frac{\left[\log P_{t, n}^{a s k}+\log P_{t, n}^{b i d}\right]}{2}
$$

where $t, n$ is the sequence of the regular-spaced in time data and $n$ is the time interval. ${ }^{13}$ Equivalently, the nth return $(\mathrm{R})$ on day $\mathrm{t}$ is defined as:

$$
R_{t, n}=P_{t, n}-P_{t, n-1}
$$

and volatility, $\mathrm{V}_{\mathrm{t}, \mathrm{n}}$, is measured as the absolute value of the 5-minute returns.

A number of previous studies have documented a strong seasonal pattern in the average 5-minute exchange rate volatility (see, for example, Bollerslev and Domowitz (1993), Dacorogna et al. (1993) and Guillaume et al. (1997)). This seasonality is also readily apparent in both the sample of Fed intervention days and the control sample days. Failure to take account of these intra-daily seasonals is likely to result in misleading statistical analyses. In this paper de-seasonalization of the volatility series is achieved using the Anderson and Bollerslev (1997ab, 1998) version of Gallant's (1981) flexible fourier form regression method.

Figures 3 and 4 shows average absolute dem-usd and yen-usd returns, respectively, for each 5-minute interval across both the control sample days and the Fed intervention days, along with estimated intra-day seasonal. The seasonal is calculated using the Andersen and Bollerslev (1997a) flexible fourier form framework, which decomposes the

\footnotetext{
${ }^{13}$ In practice the 5 -minute price series used in this paper is formed by averaging the two immediately adjacent bid and ask observations to the round 5-minute mark with weights proportional to the distance from the end of the interval.
} 
demeaned 5-minute returns into a daily volatility factor, $\sigma_{\mathrm{t}}$, a periodic component for the nth intraday interval, $\mathrm{s}_{\mathrm{t}, \mathrm{n}}$ and an i.i.d. mean zero unit variance innovation term, $\mathrm{Z}_{\mathrm{Z}, \mathrm{n}}$.

$$
R_{t, n}-E\left(R_{t, n}\right)=\frac{\sigma_{t} s_{t, n} Z_{t, n}}{N^{\frac{1}{2}}}
$$

The daily volatility component $\sigma_{\mathrm{t}}$ in practice is estimated from a MA(1)-FIGARCH(1,d,1) model for dem- usd and yen-usd fitted over 1752 daily returns from January 1989 though December 1995. And the seasonal component is estimated using a flexible fourier form (FFF) regression. Following Andersen and Bollerslev (1997a), and defining $\mathrm{x}_{\mathrm{t}, \mathrm{n}}$ from equation (1.6) as:

$$
x_{t, n} \equiv 2 \log \left[\left|R_{t, n}-E\left(R_{t, n}\right)\right|\right]-\log \sigma_{t}^{2}+\log N=\log s_{t, n}^{2}+\log Z_{t, n}^{2}
$$

the approach is then based on a non-linear regression in the intraday time interval, $\mathrm{n}$, and the daily volatility factor, $\sigma_{\mathrm{t}}$ :

$$
x_{t, n}=f\left(\theta ; \sigma_{t}, n\right)+\log Z_{t, n}^{2}-E\left(\log Z_{t, n}^{2}\right)
$$

In the actual implementation the non-linear regression function is approximated by the following parametric function:

$f\left(\theta ; \sigma_{t}, n\right)=\sum_{j=0}^{J} \sigma_{t}^{j}\left[\mu_{0 j}+\mu_{1 j} \frac{n}{N_{1}}+\mu_{2 j} \frac{n^{2}}{N_{2}}+\sum_{i=1}^{D} \lambda_{i j} I_{n=d_{i}}+\sum_{i=1}^{P}\left(\gamma_{p j} \cos \frac{2 \pi p}{N} n+\delta_{p j} \sin \frac{2 \pi p}{N} n\right)\right]$

where $\mathrm{N}_{1}=(\mathrm{N}+1) / 2$ and $\mathrm{N}_{2}=(\mathrm{N}+1)(\mathrm{N}+2) / 6$ are normalized constants, $\mathrm{N}$ refers to the number of return intervals per day $(\mathrm{N}=288)$, the tuning parameter $\mathrm{P}(\mathrm{P}=8)$ determines the order of the expansion ${ }^{14}$, the $\mathrm{J}$ flexible fourier forms are parameterized by quadratic components

\footnotetext{
${ }^{14}$ Andersen and Bollerslev (1997a, 1998) and Cai, Cheung, Lee and Melvin (2001) find that $P=6$ fits the dem-usd FXFX data over the sample 92-93 and the yen-usd FXFX data in 1998. Experimentation with
} 
(terms with $\mu$-coefficients), a number of sinusoids (the $\gamma$ and $\delta$ coefficients) and time-

specific dummies (the $\lambda$ coefficients). In practice estimation involved a two-step

procedure where $\hat{x}_{t, n}$ was replaced by the sample mean of the 5-minute returns and treated as the dependent variable in the regression defined by equations (1.6) and (1.7). Defining $\widehat{f}_{t, n}$ as the resulting estimate for the right hand side of equation (1.7), then the intraday periodic seasonal component for interval $\mathrm{n}$ on day $\mathrm{t}$ is

$$
\hat{S}_{t, n}=\frac{T \cdot \exp \left(\hat{f}_{t, n} / 2\right)}{\sum_{t=1}^{T / N} \sum_{n=1}^{N} \exp \left(\hat{f}_{t, n} / 2\right)}
$$

An "event study" approach is used to examine the influence of central bank intervention (and other macro announcements) on exchange rate volatility. ${ }^{15}$ The general regression specification is:

$$
V_{t, n}=\alpha_{0}+\sum_{k} \sum_{i} \alpha_{1, i}^{k} D_{t, n+i}^{k}+\alpha_{2} \hat{s}_{t, n}+\varepsilon_{t, n}
$$

where $\mathrm{D}^{\mathrm{k}}$ denotes the (time-stamped to the nearest 5-minute) intervention and other announcement dummy variables and $\hat{S}_{t, n}$ is the FFF volatility seasonal estimated over the control sample days. ${ }^{16}$ Using this general regression specification it is possible to test for the impact and intra-day effects of intervention (and other macro news) by examining whether the $\mathrm{D}^{\mathrm{k}} \mathrm{s}$ are statistically significant.

\footnotetext{
$\mathrm{P}=4,6$ and 8 using both the control sample and Fed intervention day samples (over the years 1989-1995), indicate that $\mathrm{P}=8$ offers the best fit with these data.

${ }^{15}$ See Dominguez (2003a) for a similar "event study" approach using returns rather than volatility.

${ }^{16}$ Estimates of the intra-daily seasonal using the Fed intervention days produced very similar results. Control sample days were used under the assumption that volatility on intervention days may differ from non-intervention days (indeed figures 3 and 4 suggest that especially for the yen-usd market Fed intervention days are more volatile than the control sample days), and while it is necessary to control for intra-day cycles, it is also important not to inadvertently explain away what is unusual about intervention days by only using intervention days to calculate the seasonal. I am grateful to Michael Melvin for suggesting I use the control sample days for this purpose.
} 
Interventions in the event study by all three central banks take the value 1 if they involve a purchase or sale of dollars and 0 otherwise. Interventions are included as $(1,0)$ dummy variables both because the dollar magnitudes are generally only available at a daily (not intra-daily) frequency, and because there is some evidence that the sizes of interventions depend on market reactions to initial trades suggesting that including magnitudes might engender simultaneity bias.

Table 7 presents the results of the volatility event-study regression using the FXFX five-minute dem-usd data. Significant one-hour leads were found for intervention operations by all three central banks, suggesting that some traders know about these operations well before the Reuters new release. ${ }^{17}$ Bundesbank interventions in the sample had the largest (positive) influence on volatility by a factor of two relative either to Fed or BOJ interventions. Fed interventions continued to influence dem-usd volatility for one hour after the Reuters report, while Bundesbank interventions had effects for 25 minutes after the report, and BOJ interventions had effects for just 10 minutes after the report. Only announcements by the Fed significantly influenced volatility. Seven of the twelve U.S. and German macro announcements are also found to be significant, with the significant lags varying from impact to fifteen minutes after the Reuters time-stamp. The announcement with the largest average influence on dem-usd variability is U.S. GNP. The intra-day seasonal is highly significant in the regression. The interventions, announcements, macro controls and seasonal together explain just under $25 \%$ of intra-day dem-usd volatility.

\footnotetext{
${ }^{17}$ Various regression specifications were attempted, including imposing a polynomial distributed lag (pdl) structure on the leads and lags of the intervention variables. Tests of the pdl restrictions suggested that the data do not conform to this specification. Experimentation with various lead and lag combinations indicated that a $[-1 \mathrm{hr},+2 \mathrm{hr}]$ window for the intervention variables and a $[0,1 \mathrm{hr}]$ window for the macroeconomic announcements was appropriate.
} 
The results of the yen-usd volatility event-study regression are presented in Table 8. In contrast to the analogous dem-usd regression, Bundesbank interventions are not statistically significant. There is evidence of one-hour Reuters announcement lags for both the Fed and the BOJ. Fed interventions continue to have effects for an hour and a half after the Reuters report, and BOJ interventions continue to have effects for one hour after the report. Both Fed and BOJ central bank announcements also influence volality. Six of twelve U.S. and Japanese macro announcements are significant. U.S. GNP again has the largest effect.

Tables 7 and 8 include results from three alternative regression specifications. The first of these alternative hypotheses asks whether the relationship between interventions and volatility is related to the volume of trade. In particular, the regressions test whether Fed interventions that occurred during the overlap in New York and European trading, when volume is generally highest, had different effects than those that occurred during other time periods. The results for both the dem-usd and yen-usd suggest that, regardless of volume, Fed interventions have statistically significant effects over the 36 (5-min) leads and lags. In both the high and low trade volume times, Fed interventions continued to have one-hour lead effects and roughly one-hour lag effects in the dem-usd market, and onehour and twenty minute lag effects in the yen-usd market. Results for the remaining variables in the regression were little changed by the inclusion of the interactive trade volume dummy. The relative size of the coefficients on Fed intervention in low and high volume trade volume suggests Fed interventions during high volume periods in the yen-usd market had a slightly larger overall effect, and it is worth noting that $61 \%$ of Fed interventions occurred during high trade volume times. 
The second alternative specification serves as a test of whether interventions that are timed close to a (scheduled) macro announcement have different effects than those that are not. The dummy variable distinguishing those interventions that occurred within a twohour window of a macro announcement are significant in both the dem-usd and yen-usd volatility regressions. The relative size of the coefficients on the interactive dummy suggests that these interventions have larger effects on volatility than interventions that are not timed close to other announcements (although these continue to be significant in the regressions). One possible explanation for this result is that traders are more sensitive to news (including intervention news) at times when other major announcements are released..$^{18}$

The final set of alternative specifications examines the extent to which coordination matters. Interventions are defined as being "coordinated" if at least one other of the G3 central banks intervened within a two hour window (and in the same direction). In the case of the dem-usd market, $31 \%$ of all Fed interventions over this period were coordinated with the Bundesbank. The results suggest that those interventions that were coordinated have a slightly larger influence on volatility than unilateral interventions. Interestingly, the lag effects for coordinated interventions last a good hour beyond those for unilateral interventions. In the yen-usd market, $54 \%$ of all Fed interventions over this period were coordinated with the BOJ. Results again suggest that both coordinated and unilateral Fed interventions influence volatility, though the size of the effect is actually larger for unilateral interventions. As in the dem-usd market, coordinated interventions had

\footnotetext{
${ }^{18}$ Evans and Lyons (2002b) also find that currency trades have greater price impact if they are closely timed with macro announcements.
} 
significant lag effects on yen-usd volatility for an hour and a half after the Reuters report, while the influence of unilateral interventions lasted for about forty-five minutes.

The event study results indicate that G3 interventions systematically influenced intra-day exchange rate volatility over the sample period examined, August 1989 through August 1995. The coefficient estimates indicate that Reuters reports generally lag interventions by one hour, and intervention continues to influence volatility up to one and a half hours after the Reuters report release, suggesting that intervention is neither common knowledge, nor perfectly informative. It is also worth noting that all the coefficients on intervention in tables 7 and 8 are positive, indicating that in the very short run interventions are always associated with increases in volatility.

The next set of tests, reported in Tables 9, 10 and 11, examine the influence of G3 interventions on daily volatility ${ }^{19}$. Recall from the model in section II that trader heterogeneity can make even informative intervention increase very short run exchange rate volatility, though over time interventions should become common knowledge, and traders should sort out any misinterpretation of intervention's information content. Daily realized dem-usd and yen-usd volatility is measured using the intra-daily returns data. Following Anderson and Bollerslev (1998) we sum the squared 5-minute FXFX indicative quote returns over each day (through GMT22) ${ }^{20}$, such that:

$$
\sigma_{t}^{F X F X}=\sqrt{\sum_{n=1}^{264} R_{t, n}^{2}}
$$

\footnotetext{
${ }^{19}$ A number of papers have examined the influence of intervention on daily exchange rate volatility. See, for example, Bonser-Neal and Tanner (1996), Dominguez (1998), Chaboud and LeBaron (2001), Galati, Melick and Micu (2002), Frenkel, Pierdzioch, and Stadtmann (2003) and Beine (2003).

${ }^{20}$ The daily integrated volatilities were created by Steve Weinberg. The daily cutoff is GMT22 when volatility is generally very low. Weekends are excluded and the volatilities are expressed as annualized standard deviations.
} 
to create a daily integrated volatility series. This measure better captures current volatility relative to standard models such as GARCH because it is able to exploit contemporaneous intraday information. As Anderson, Bollerslev, Diebold and Labys (2003) explain,

"Suppose, for example, that the true volatility has been low for many days, $t=1, \ldots T-1$, so that both realized and GARCH volatilities are presently low as well. Now suppose that the true volatility increases sharply on day $T$ and that the effect is highly persistent as is typical. Realized volatility for day, $T$, which makes effective use of the day- $T$ information, will increase sharply as well, as is appropriate. GARCH or RiskMetrics volatility, in contrast, will not change at all on day $T$, as they depend only on squared returns from days $T-1, T-2, \ldots$, and they will increase only gradually on subsequent days, as they approximate volatility via a long and slowly decaying exponentially weighted moving average."

In the context of measuring the impact of interventions on volatility - it is particularly

important that our measure of volatility reflect current (and not necessarily past) market

conditions. Figures 5 and 6 show the integrated volatility series as well as a MA(1)-

GARCH(1,1) volatility measure for the dem- usd and yen- usd, respectively.

Unsurprisingly the GARCH series are much smoother than the integrated volatility series, though both sets of volatilities tend to move together.

Table 9 presents statistics on the distribution of the logarithm of realized volatility for dem- usd and yen-usd, over the full sample period as well as on intervention days. For the full sample (and non-intervention days sample) the measures of skewness and kurtosis suggest the series are approximately Gaussian and the Ljung-Box statistics indicate strong serial correlation. ${ }^{21}$ Further, the estimates of the degree of fractional

\footnotetext{
${ }^{21}$ Five observations in the dem-usd realized volatility series were significant outliers and are excluded from the sample. Realized volatility on September 14, 1992 is two times higher than the second highest day and realized volatilities on Septemb er 3-4, 1991and May 12-13, 1994 are three times smaller than the next lowest day. We replaced these outliers with values from the next highest (or lowest) realized volatilities in the sample distribution. Replacing these outliers does not significantly change the regression results in Table 10, but does influence the skewness and kurtosis statistics for the full and non-intervention
} 
integration, $\mathrm{d}$, are significantly greater than zero and less than .5, which indicates evidence of long-run dependence in the logarithmic volatilities. It is interesting to note that on "all" interventions days, and particularly on coordinated intervention days, the mean realized volatility is significantly larger than on non-intervention days. Realized volatility on the day after an intervention remains higher for the dem- usd but not for yenusd, and volatility on the day before an intervention is no higher, on average, than on other non-intervention days.

The statistics in table 9 suggest that the long-memory dynamics of the realized logarithmic volatilities are best modeled using a fractional integration or ARFIMA (autoregressive, fractionally integrated, moving average) model. Experimentation with the two realized volatility series suggests that for the dem- usd an ARFIMA(1,d,0) best describes the data, while for the yen-usd we use an $\operatorname{ARFIMA}(0, \mathrm{~d}, 0)$ model. In order to test whether daily interventions are correlated with realized volatility we include a holiday dummy variable $(\mathrm{H})$ to control for holiday and market closure effects as well as daily contemporaneous and lagged G3 intervention indicators (the $\mathrm{D}^{\mathrm{k}} \mathrm{s}$ ) as explanatory variables:

$$
\begin{aligned}
& (1-L)^{d}(1-\phi L)\left(v_{t}-\mu_{t}\right)=\varepsilon_{t}, \\
& \mu_{t}=\alpha_{0}+\alpha_{1}^{k} D_{t}^{k}+\alpha_{2} H_{t}, \\
& \varepsilon_{t} \sim N(0, \omega)
\end{aligned}
$$

where $d$ is the fractional parameter, $L$ denotes the lag operator, $\phi$ denotes the AR parameter (set to 0 in the case of yen-usd), $v_{t}$ denotes the log of the integrated volatility 
$\left(\sigma^{\text {FXFX }}\right.$ ) at time $t, \alpha_{0}$ is an intercept, $\alpha_{1}^{k}$ is the intervention parameter vector, and $\alpha_{2}$ is the holiday parameter. ${ }^{22}$

The results in table 10 indicate that coordinated interventions continue to systematically influence daily contemporaneous dem-usd and yen-usd volatility, though there is no evidence that the influence of coordinated interventions extends beyond the day of the operations. Similarly, contemporaneous unilateral Fed, Bundesbank and BOJ operations all influence daily realized volatility in both markets. In the yen-usd market unilateral Fed interventions are marginally significant after 3 days. The relative magnitudes of the coefficients in the daily regressions suggest that coordinated interventions have a substantially larger impact on daily volatility than do unilateral interventions. Coordinated operations were also significant in the intra-day tests, though the relative size of the coefficients on coordinated and unilateral operations were similar. This suggests that over the course of the day the influence of coordinated operations (which may have a lower probability of containing non-fundamental information) increases. Overall, the results in tables 7-10 indicate that interventions by all three central banks positively influenced intraday and daily (contemporaneous) exchange rate volatility. There is little evidence that interventions systematically influence volatility beyond the day of the operations. ${ }^{23}$

The ARFIMA model specification in 1.13 implicitly assumes that shocks on intervention days are as persistent as shocks on non-intervention days. A final set of

\footnotetext{
${ }^{22}$ Estimation is based on the numerical quasi-maximum likelihood (QML) algorithm, where the likelihood function is based on the Wold representation of the ARFIMA(1,d,0) processes with a Gaussian assumption. The $t$-statistics reported in the tables are calculated using the corresponding heteroskedastic-consistent standard errors based on finite difference approximation.

${ }^{23}$ One day leads of coordinated and unilateral Fed interventions were also included in the regression specification but lead coefficients were never statistically significant and are not reported in table 10 . These results are available from the author upon request.
} 
regressions tests whether this assumption is valid by allowing the persistence of volatility to differ across intervention and non-intervention days ${ }^{24}$, specifically:

$$
\begin{aligned}
& v_{t}=\alpha_{0}^{n}+v_{t}^{n}+v_{t}^{I}+\alpha_{2} D_{t}^{I}+\alpha_{3} H_{t}+\varepsilon_{t} \\
& v_{t}^{n}=\alpha_{1}^{n}\left(1-D_{t-1}^{I}\right) \varepsilon_{t-1}+\beta^{n} v_{t-1}^{n} \\
& v_{t}^{I}=D_{t-1}^{I}\left(\alpha_{0}^{I}+\alpha_{1}^{I} \varepsilon_{t-1}\right)+\beta^{I} v_{t-1}^{I} \\
& \varepsilon_{t} \sim N(0, \omega)
\end{aligned}
$$

where $v_{t}^{n}$ and $v_{t}^{I}$ are daily realized volatility on non-intervention and intervention days, respectively. Note that if $\alpha_{0}^{I}=0, \alpha_{1}^{n}=\alpha_{1}^{I}$, and $\beta^{n}=\beta^{I} 1.14$ approximately reduces to an ARMA(1,1) model. Regression estimates of this model are given in Table 11 and indicate that the persistence of shocks on intervention and non-intervention days is not statistically different. The likelihood ratio statistics suggest that we cannot reject the joint hypothesis that $\alpha_{0}^{I}=0, \alpha_{1}^{n}=\alpha_{1}^{I}$ and $\beta^{n}=\beta^{I}$. Further, the estimates of $\beta^{I}$ (the coefficient on lagged volatility on intervention days) suggest that the effects of shocks to volatility on intervention days fall by half in 1.5 days for dem-usd and 3 days for yen-usd.

\section{Conclusions}

This paper identifies circumstances in which central bank interventions influence exchange rates. Microstructure theory suggests that trader heterogeneity can cause exchange rates to move away from fundamentals in the short-run. Introducing intervention operations into an already confused market, in turn, can increase the influence of nonfundamentals trading on exchange rate movements. Over time, however, interventions are common knowledge and traders should be able to distinguish informative from non-

\footnotetext{
${ }^{24}$ Jones, Lamont and Lumsdaine (1998) estimate a similar model to measure the influence of macroeconomic information on the persistence of bond market volatility.
} 
informative interventions. This suggests that the influence of interventions on exchange rates may well differ over the very short and longer runs.

The empirical tests in this paper examine the influence of G3 interventions on demusd and yen-usd intra-daily (5-minute) indicative quote volatility as well as a measure of realized daily volatility. Results suggest that intervention operations, especially those that were coordinated, were consistently associated with increases in intra-day and daily volatility, while there is little evidence that interventions influenced longer-term volatility. The fact that interventions did not lead to longer-term increases in volatility may help explain why governments, who presumably prefer not to increase market volatility, continue to rely on interventions to influence currency values. 


\section{References}

Almeida, A., Goodhart, C., Payne, R., 1998, The Effects of Macroeconomic News on High Frequency Exchange Rate Behavior, Journal of Financial and Quantitative Analysis, 33 (3), 383408.

Andersen, T. and Bollerslev, T., 1997a. Intraday Periodicity and Volatility Persistence in Financial Markets, Journal of Empirical Finance, 4, 115-158.

Andersen, T. and Bollerslev, T. 1997b Heterogeneous Information Arrivals and Return Volatility Dynamics: Uncovering the Long-Run in High Frequency Returns, Journal of Finance, 975-1005.

Andersen, T. and Bollerslev, T., 1998. Deutsche Mark-Dollar Volatility: Intraday Activity Patterns, Macroeconomic Announcements, and Longer Run Dependencies, Journal of Finance, 53(1) 219-65.

Andersen, T., Bollersleb, T., Diebold, F. and Labys, P., 2003, Modeling and Forecasting Realized Volatility, Econometrica, 71, 529-626.

Andersen, T., Bollerslev, T. Diebold, F. and Vega, C., 2003 Micro Effects of Macro Announcements: Real Time Price Discovery in Foreign Exchange, American Economic Review, 93(1), 38-62.

Bacchetta, P. and van Wincoop, E., 2003, Can Information Heterogeneity Explain the Exchange Rate Determination Puzzle?, NBER Working Paper \#9498, February.

Beine, M., 2003, "Volatility Expectations and the Asymmetric Effects of Direct Interventions in the FX Market, Journal of the Japanese and International Economies, 17, 55-80.

Beattie, N., Fillion, J., 1999. An Intraday Analysis of the Effectiveness of Foreign Exchange Intervention. Bank of Canada Working Paper 99-4.

Bollerslev, T. and Domowitz, I., 1993 Trading Patterns and Prices in the Interbank Foreign Exchange Market. Journal of Finance, 48, 1421-1443.

Bonser-Neal, C. and Tanner, G., 1996 Central Bank Intervention and the Volatility of Foreign Exchange Rates: Evidence from the Options Market. Journal of International Money and Finance 15/6, 853-878.

Cai, J., Cheung, Y., Lee, R., Melvin, M. 2001 'Once-in-a-Generation' Yen Volatility in 1998: Fundamentals, Intervention and Order Flow. Journal of International Money and Finance, 20, 327-347.

Chaboud, A., LeBaron, B., 2001. Foreign Exchange Market Trading Volume and Federal Reserve Intervention. Journal of Futures Markets, 21, 851-860.

Chang, Y., Taylor, S., 1998. Intraday Effects of Foreign Exchange Intervention by the Bank of Japan. Journal of International Money and Finance 18, 191-210. 
Dacorogna, M.M., U.A. Muller, R.J. Nagler, R.B. Olsen, and O.V. Pictet, 1993. A Geographical Model for the Daily and Weekly Seasonal Volatility in the FX Market. Journal of International Money and Finance 12, 413-438.

Danielsson, J. and Payne, R., 2002 Real Trading Patterns and Prices in Spot Foreign Exchange Markets: An Empirical Investigation, Journal of International Money and Finance, 21, 203-222.

De Grauwe, P. and Grimaldi, M., 2003, Intervention in the Foreign Exchange Market in a Model with Noise Traders, mimeo, May.

Dominguez, K., 1998. Central Bank Intervention and Exchange Rate Volatility, Journal of International Money and Finance 18, 161-190.

Dominguez, K., 2003a. The Market Microstructure of Central Bank Intervention. Journal of International Economics 59, 25-45.

Dominguez, K., 2003b Foreign Exchange Intervention: Did it Work in the 1990s? in Dollar Overvaluation and the World Economy, edited by C.F. Bergsten and J. Williamson, Institute for International Economics, Special Report 16, 217-245.

Dominguez, K., Frankel, F., 1993a. Does Foreign Exchange Intervention Matter ? The Portfolio Effect. American Economic Review 83, 1356-69.

Dominguez, K., Frankel, F., 1993b. Does Foreign Exchange Intervention Work? Institute for International Economics, Washington, D.C.

Edison, H., 1993 The Effectiveness of Central Bank Intervention: A Survey of Post-1982 Literature. Essays in International Finance, Princeton University Press, Princeton.

Evans, M,, Lyons, R., 2001. Portfolio Balance, Price Impact and Secret Intervention. National Bureau of Economic Research Working Paper 8356.

Evans, M., Lyons, R., 2002 Time-Varying Liquidity in Foreign Exchange, Journal of Monetary Economics, 49(5) 1025-1051.

Evans, M., Lyons, R., 2002 Order Flow and Exchange Rate Dynamics, Journal of Political Economy, 170-180.

Fischer, A.M., Zurlinden, M., 1999. Exchange Rate Effects of Central Bank Interventions: An Analysis of Transaction Prices. Economic Journal 109, 662-676.

Frenkel, M. Pierdzioch, C. and Stadtmann, G. 2003 The Effects of Japanese Foreign Exchange Market Interventions on the Yen/US Dollar Exchange Rate Volatility, Kie1 Working Paper No. 1165. 
Galati, G., Melick, W. Micu, M., 2002, Foreign Exchange Market Intervention and Expectations: An Empirical Study of the Dollar/Yen Exchange Rate, August mimeo.

Gallant, R. 1981 On the Bias in Flexible Functional Forms and an Essentially Unbiased Form: The Fourier Flexible Form, Journal of Econometrics, 15(2), 211-45.

Goodhart, C., Hesse, T., 1993. Central Bank Forex Intervention Assessed in Continuous Time. Journal of International Money and Finance 12, 368-389.

Goodhart, C., Ito, T., Payne, R., 1996. One Day in June 1993: A Study of the Working of the Reuters 2000-2 Electronic Foreign Exchange Trading System in: Frankel, J., Galli, G., Giovannini, A., (Eds.), The Microstructure of Foreign Exchange Markets, The University of Chicago Press for NBER, pp.107-179.

Guillaume, D., Dacorogna, M., Dave, R., Muller, U., Olsen, R., Pictet, O., 1997. From the Bird's Eye to the Microscope: A Survey of New Stylized Facts on the Intra-Daily Foreign Exchange Markets. Finance and Stochastics 1(2), 95-129.

Humpage, O., 1999, U.S. Intervention: Assessing the Probability of Success. Journal of Money, Credit and Banking, vol31, No. 4, November, 731-747.

Ito, T., forthcoming, "Is Foreign Exchange Intervention Effective?: The Japanese experiences in the 1990s" in Paul Mizen (ed.), Monetary History, Exchange Rates and Financial Markets, Essays in Honour of Charles Goodhart, Volume 2, Cheltenham U.K.; Edward Elgar Publishers and NBER working paper no. 8914 (April 2002).

Jones, C., Lamont, O., and Lumsdaine, R., 1998, Macroeconomic News and Bond Market Volatility, Journal of Financial Economics, 47, 3, 315-337.

LeBaron, B., 1999. Technical Trading Rule Profitability and Foreign Exchange Intervention. Journal of International Economics 49, 1, 125-143.

Lyons, R., 2001. The Microstructure Approach to Exchange Rates, MIT Press.

Neely, C., 2000. The Practice of Central Bank Intervention: Looking Under the Hood. Central Banking Vol. XI, No.2, 24-37.

Neely, C., 2002, The Temporal Pattern of Trading Rule Returns and Central Bank Intervention: Intervention Does Not Generate Technical Trading Rule Profits. Journal of International Economics, 58, 211-232.

O'Hara, M., 1995. Market Microstructure Theory, Blackwell Business.

Pasquariello, P., 2001 Central Bank Intervention and the Intraday Process of Price Formation in the Currency Markets, Stern School of Business, NYU. 
Pasquariello, P., 2002 Informative Trading or Just Noise? An Analysis of Currency Returns, Market Liquidity, and Transaction Costs in Proximity of Central Bank Interventions, Stern School of Business, NYU, November.

Payne, R., Vitale, P., forthcoming, A Transaction Level Study of the Effects of Central Bank Intervention on Exchange Rates. Journal of International Economics.

Peiers, B., 1997. Informed Traders, Intervention and Price Leadership: A Deeper View of the Microstructure of the Foreign Exchange Market. Journal of Finance 52(4), 1589-1614.

Sarno, L., Taylor, M., 2001 Official Intervention in the Foreign Exchange Market: Is it Effective and, If So, How Does it Work? Journal of Economic Literature, vol. XXXIX, September, 839-868.

Taylor, M. 2003 Is Official Exchange Rate Intervention Effective? CEPR Discussion Paper No. 3758. 
Table 1 Timing of Selected Reuters Announcements (1989-1995)

\begin{tabular}{|l|l|l|}
\hline News Event & Day-of-week & $\begin{array}{l}\text { Average time } \\
\text { (GMT) }\end{array}$ \\
\hline Fed Intervention & & \\
\hline US Employment & various & $14: 57: 10$ \\
\hline US CPI/PPI & Friday & $12: 30(\mathrm{DST}) ; 13: 30$ \\
\hline US M1 & Friday & $12: 30(\mathrm{DST}) ; 13: 30$ \\
\hline US Trade & Thursday & $20: 30(\mathrm{DST}) ; 21: 30$ \\
\hline US Consumer Credit & various & $12: 30(\mathrm{DST}) ; 13: 30$ \\
\hline US Retail Sales & various & $19: 30(\mathrm{DST}) 20: 30$ \\
\hline US Leading Indicators & various & $12: 30(\mathrm{DST}) ; 13: 30$ \\
\hline US GNP & Wed or Fri & $12: 30(\mathrm{DST}) ; 13: 30$ \\
\hline FOMC news & various & $12: 30(\mathrm{DST}) ; 13: 30$ \\
\hline comments by US officials & Friday & $20: 30(\mathrm{DST}) ; 21: 30$ \\
\hline & various & $14: 48: 12$ \\
\hline Bundesbank Intervention & various & $11.31: 16$ \\
\hline Bundesbank Meeting & Thursday & $11: 30(\mathrm{DST}): 12: 30$ \\
\hline German M3 & various & $6: 30(\mathrm{DST}) ; 7: 30$ \\
\hline comments by German officials & various & $10: 27: 13$ \\
\hline & \multicolumn{2}{|l}{} \\
\hline BOJ Intervention & various & $3: 56: 36$ \\
\hline Japanese Current Account & various & $6: 30(\mathrm{DST}) ; 7: 30$ \\
\hline comments by Japanese officials & various & $6: 51: 07$ \\
\hline DST denotes & oflight savings & otimer \\
\hline
\end{tabular}

DST denotes daylight savings time; otherwise, times are GMT.

Table 2 Typical timing of G3 interventions during the 24 hour GMT clock

\begin{tabular}{|c|c|c|c|c|c|c|c|}
\hline & GMT24(t-1) & GMT3 & GMT8 & GMT11 & GMT14 & GMT17 & GMT22 \\
\hline Tokyo & 9am & $12 \mathrm{pm}$ & $5 \mathrm{pm}$ & & & & \\
\hline & \multicolumn{3}{|c|}{ BOJ interventions } & & & & \\
\hline Frankfurt & & & $9 \mathrm{am}$ & $12 \mathrm{pm}$ & $3 \mathrm{pm}$ & $6 \mathrm{pm}$ & \\
\hline & & & \multicolumn{7}{|c|}{ Bundesbank Interventions } & \\
\hline New York & & & & & $9 \mathrm{am}$ & $12 \mathrm{pm}$ & $5 \mathrm{pm}$ \\
\hline & & & & & \multicolumn{7}{c|}{ Fed Interventions } \\
\hline
\end{tabular}

GMT is Greenwich Mean Time. 
Table 3 G3 Central Bank Intervention Descriptive Statistics 1989-1995

\begin{tabular}{|l|l|l|l|l|}
\hline & Fed & Buba & BOJ & $\begin{array}{l}\text { Any } \\
\text { CB }\end{array}$ \\
\hline Number of intervention days & 104 & 39 & 63 & 206 \\
\hline Total number of intra-day interventions & 268 & 83 & 145 & 496 \\
\hline $\begin{array}{l}\text { Probability of a } 2^{\text {nd }} \text { intervention within 1 hour of } \\
\text { prior one }\end{array}$ & 0.56 & 0.29 & 0.26 & 0.49 \\
\hline $\begin{array}{l}\text { Number of interventions followed by another one } \\
\text { within 1 hour }\end{array}$ & 156 & 24 & 37 & 244 \\
\hline Total number of intervention clusters & 44 & 25 & 16 & 83 \\
\hline $\begin{array}{l}\text { Average duration of intervention clusters, } \\
\text { each 1 hour apart }\end{array}$ & $0: 44: 49$ & $0: 45: 30$ & $0: 35: 08$ & $0: 42: 48$ \\
\hline Average number of interventions in a cluster & 5.023 & 2.52 & 2.5 & 4.048 \\
\hline
\end{tabular}

Note: An intervention cluster is defined as at least two interventions that occur within the same hour.

Table 4 Timing of G3 Central Bank Interventions in the dem- usd and yen- usd markets

\begin{tabular}{|l|l|l|}
\hline & Dem-usd & yen-usd \\
\hline Percent of Interventions closely timed with macro announcements & & \\
\hline 1. all interventions (any bank) & $7 \%$ & $10 \%$ \\
\hline 2. Fed interventions & $7 \%$ & $13 \%$ \\
\hline 3. Buba interventions & $6 \%$ & $15 \%$ \\
\hline 4. BOJ interventions & $9 \%$ & $4.5 \%$ \\
\hline Percent of Fed Interventions & & \\
\hline 1. occurring before 12:00 est & $42.6 \%$ & $57 \%$ \\
\hline 2. occurring after 12:00 est & $13.4 \%$ & $16 \%$ \\
\hline 3. unknown & $0.004 \%$ & $3 \%$ \\
\hline 4. occurring in both the am and pm & $44 \%$ & $24 \%$ \\
\hline Percent of Fed Interventions occurring during European Trading & $61 \%$ & $61 \%$ \\
\hline Percent of Fed Interventions Coordinated & & \\
\hline 1. with Buba & $31 \%$ & \\
\hline 2. with BOJ & & $54 \%$ \\
\hline
\end{tabular}

Note: "closely timed" is defined as occurring within 2 hours. Likewise, "coordinated" Fed interventions are defined as interventions that occur within 2 hours of a BOJ or Bundesbank intervention. 
Table 5 The 25 Largest 5-min dem-usd Returns (1989-95)

\begin{tabular}{|l|l|l|l|l|}
\hline DATE & TIME & RETURN & \multicolumn{1}{|l|}{ EVENT } & REUTERS TIME-STAMP \\
\hline & & & & \\
\hline $9 / 15 / 89$ & $12: 35: 00$ & 0.009458 & CPI;Trade & $12: 36 ; 12: 36$ \\
\hline $9 / 15 / 89$ & $18: 20: 00$ & 0.005188 & Fed & $13: 56$ \\
\hline $9 / 15 / 89$ & $18: 25: 00$ & 0.011564 & BB & $14: 28$ \\
\hline $10 / 5 / 89$ & $13: 05: 00$ & 0.005004 & BB & $12: 09$ and $13: 11$ \\
\hline $10 / 6 / 89$ & $12: 35: 00$ & 0.005968 & Employment & $12: 34$ \\
\hline $1 / 10 / 90$ & $15: 15: 00$ & 0.006123 & Fed & $19: 05$ \\
\hline $3 / 19 / 91$ & $13: 10: 00$ & 0.00525 & Fed;BB & $16: 00-16: 13$ \\
\hline $3 / 19 / 91$ & $13: 40: 00$ & 0.00514 & CPI;Housing Starts & $13: 33$ \\
\hline $3 / 19 / 91$ & $14: 35: 00$ & 0.005161 & Fed;BB & $16: 00-16: 13$ \\
\hline $3 / 19 / 91$ & $14: 40: 00$ & 0.005647 & Fed;BB & $16: 00-16: 13$ \\
\hline $3 / 19 / 91$ & $14: 45: 00$ & 0.008245 & Fed;BB & $16: 00-16: 13$ \\
\hline $5 / 17 / 91$ & $14: 30: 00$ & 0.007094 & Fed;BB & $19: 15-20: 53$ \\
\hline $5 / 17 / 91$ & $14: 35: 00$ & 0.005674 & Fed;BB & $19: 15-20: 53$ \\
\hline $5 / 17 / 91$ & $15: 05: 00$ & 0.005492 & Fed;BB & $19: 15-20: 53$ \\
\hline $7 / 12 / 91$ & $13: 25: 00$ & 0.005715 & Fed;BB & $13: 27$ \\
\hline $7 / 20 / 92$ & $14: 20: 00$ & 0.005532 & Fed;BB & $14: 30$ \\
\hline $7 / 20 / 92$ & $14: 30: 00$ & 0.006298 & Fed;BB & $14: 30$ \\
\hline $8 / 11 / 92$ & $12: 20: 00$ & 0.005553 & Fed;BB & $12: 30$ \\
\hline $8 / 21 / 92$ & $13: 25: 00$ & 0.006027 & Fed;BB & $13: 35$ \\
\hline $4 / 29 / 94$ & $14: 30: 00$ & 0.006037 & Fed & $14: 40$ \\
\hline $11 / 2 / 94$ & $16: 05: 00$ & 0.007848 & Fed & $16: 13-18: 53$ \\
\hline $5 / 31 / 95$ & $12: 40: 00$ & 0.010738 & Fed & $12: 49$ \\
\hline $5 / 31 / 95$ & $12: 45: 00$ & 0.005854 & BB & $12: 45$ \\
\hline $5 / 31 / 95$ & $12: 55: 00$ & 0.006077 & Fed & $12: 51-12: 54$ \\
\hline $8 / 15 / 95$ & $12: 20: 00$ & 0.008128 & BB;Fed;BOJ & $12: 49-12: 58$ \\
\hline
\end{tabular}

NOTE: At least one Fed interventions occurred on each of the days in the sample.

* Events are defined as any macro announcement or central bank intervention that occurred within a [-1hr,5hr] window of the large return. 
Table 6 The 25 Largest 5-min yen-usd Returns (1989-95)

\begin{tabular}{|l|l|l|l|l|}
\hline DATE & TIME & RETURN & \multicolumn{1}{|c|}{ EVENT* } & REUTERS TIME-STAMP \\
\hline & & & & \\
\hline $9 / 15 / 89$ & $12: 35: 00$ & 0.005344 & CPI;Trade;Fed;BB & $12: 36 ; 12: 36 ; 13: 56 ; 14: 28$ \\
\hline $9 / 15 / 89$ & $18: 20: 00$ & 0.007393 & Fed;BB & $13: 56 ; 14: 28$ \\
\hline $9 / 15 / 89$ & $18: 25: 00$ & 0.005687 & Fed;BB & $13: 56 ; 14: 28$ \\
\hline $9 / 15 / 89$ & $18: 35: 00$ & 0.006791 & Fed;BB & $13: 56 ; 14: 28$ \\
\hline $10 / 6 / 89$ & $12: 35: 00$ & 0.005976 & Employment;Fed & $12: 34 ; 13: 42$ \\
\hline $1 / 17 / 92$ & $18: 35: 00$ & 0.005997 & Fed & $18: 38$ \\
\hline $1 / 17 / 92$ & $19: 10: 00$ & 0.005314 & BOJ & $19: 14$ \\
\hline $1 / 17 / 92$ & $19: 15: 00$ & 0.004613 & BOJ & $19: 14$ \\
\hline $4 / 27 / 93$ & $12: 55: 00$ & 0.004626 & Fed & $13: 05-14: 15$ \\
\hline $8 / 19 / 93$ & $12: 35: 00$ & 0.005207 & Trade & $12: 30$ \\
\hline $8 / 19 / 93$ & $14: 30: 00$ & 0.005635 & Fed & $14: 39$ \\
\hline $8 / 19 / 93$ & $15: 05: 00$ & 0.005217 & Fed & $15: 07$ \\
\hline $4 / 29 / 94$ & $13: 10: 00$ & 0.005025 & Fed & $14: 38-16: 08$ \\
\hline $5 / 4 / 94$ & $12: 30: 00$ & 0.005113 & Fed;BB & $12: 33 ; 12: 34$ \\
\hline $6 / 24 / 94$ & $13: 15: 00$ & 0.005839 & Fed;BB;BOJ & $13: 45-16: 59$ \\
\hline $6 / 24 / 94$ & $13: 35: 00$ & 0.005378 & Fed;BB;BOJ & $13: 45-16: 59$ \\
\hline $11 / 2 / 94$ & $16: 05: 00$ & 0.007266 & Fed & $16: 13-18: 58$ \\
\hline $5 / 31 / 95$ & $12: 40: 00$ & 0.008712 & Fed & $12: 49$ \\
\hline $5 / 31 / 95$ & $12: 45: 00$ & 0.008348 & BB & $12: 45$ \\
\hline $5 / 31 / 95$ & $12: 55: 00$ & 0.007176 & Fed & $12: 51-12: 54$ \\
\hline $5 / 31 / 95$ & $14: 30: 00$ & 0.004466 & Fed & $13: 47$ \\
\hline $8 / 2 / 95$ & $13: 10: 00$ & 0.005012 & Fed;BOJ & $13: 13 ; 13: 30$ \\
\hline $8 / 15 / 95$ & $12: 20: 00$ & 0.005948 & BB;Fed;BOJ & $12: 49 ; 12: 58$ \\
\hline $8 / 15 / 95$ & $23: 25: 00$ & 0.004811 & Fed;BB;US Retail Sales & $14: 28 ; 14: 24 ; 19: 06$ \\
\hline $8 / 15 / 95$ & $24: 00: 00$ & 0.004664 & Fed;BB;US Retail Sales & $14: 28 ; 14: 24 ; 19: 06$ \\
\hline
\end{tabular}

NOTE: At least one Fed intervention occurred on each of the days in the sample.

* Events are defined as any macro announcement or central bank intervention that occurred within a $[-1 \mathrm{hr}, 5 \mathrm{hr}]$ window of the large return. 
Table 7 Influence of Interventions on Intra-Day dem- usd Volatility

$$
V_{t, n}=\alpha_{0}+\sum_{k} \sum_{i} \alpha_{1, i}^{k} D_{t, n+i}^{k}+\alpha_{2} \hat{s}_{t, n}+\varepsilon_{t, n}
$$

where $\mathrm{V}$ is 5 -min dem-usd volatility (measured as the absolute value of the 5-min returns); the $\mathrm{D}^{\mathrm{k}} \mathrm{s}$ include intervention, official central bank announcements and macro announcements; $i=-1$ to $+2 \mathrm{hrs}$ for the $\mathrm{G}-3$ intervention variables and official announcements and $\mathrm{i}=0$ to $+1 \mathrm{hr}$ for the macro announcements; $\mathrm{t}, \mathrm{n}$ is the sequence of the regular-spaced (every 5 minutes) intra-daily data for all the days on which the Fed interve ned against the mark from 1989 to 1995 (69 days and a total of 151 reports of Fed operations). The reported coefficients are multiplied by 100 .

\begin{tabular}{|c|c|c|c|c|}
\hline & $\begin{array}{l}\text { Do All G-3 } \\
\text { Interventions } \\
\text { Matter? }\end{array}$ & $\begin{array}{l}\text { Does Trade } \\
\text { Volume } \\
\text { Matter? }^{1}\end{array}$ & $\begin{array}{l}\text { Does } \\
\text { Proximity to } \\
\text { Macro News } \\
\text { Matter? }^{2}\end{array}$ & $\begin{array}{l}\text { Does } \\
\text { Coordination } \\
\text { Matter? }\end{array}$ \\
\hline Independent Variable & Coeff sum ${ }^{4}$ & Coeff sum & Coeff sum & Coeff sum \\
\hline Fed Intervention & $0.121 * *$ & & & \\
\hline Buba Intervention & $0.213 * *$ & $0.212 * *$ & $0.214^{* *}$ & $\mathrm{Na}$ \\
\hline BOJ Intervention & $0.103 * *$ & $0.103 * *$ & $0.104 * *$ & $\mathrm{Na}$ \\
\hline Official Announcements & Yes & Yes & Yes & Yes \\
\hline Macro Controls & Yes & Yes & Yes & Yes \\
\hline $\begin{array}{l}\text { Fed Interventions } \\
\text { During High Trade } \\
\text { Volume }\end{array}$ & & $0.122 * *$ & & \\
\hline $\begin{array}{l}\text { Fed Interventions } \\
\text { During Low Trade } \\
\text { Volume }\end{array}$ & & $0.121 * *$ & & \\
\hline $\begin{array}{l}\text { Fed Interventions Close } \\
\text { to Macro News }\end{array}$ & & & $0.138 * *$ & \\
\hline $\begin{array}{l}\text { Isolated } \\
\text { Fed Interventions }\end{array}$ & & & $0.116^{* *}$ & \\
\hline $\begin{array}{l}\text { Coordinated } \\
\text { G-3 Interventions }\end{array}$ & & & & $0.139 * *$ \\
\hline $\begin{array}{l}\text { Unilateral } \\
\text { Fed Interventions }\end{array}$ & & & & $0.122^{*}$ \\
\hline FFF Seasonal & $0.169 * *$ & $0.169 * *$ & $0.169 * *$ & $0.173 * *$ \\
\hline $\mathrm{R} 2$ & 0.237 & 0.237 & 0.237 & 0.236 \\
\hline D.W. & 1.99 & 1.99 & 1.99 & 1.99 \\
\hline
\end{tabular}

Number of observations $=19,833 .{ }^{1}$ High trade volume is defined as the overlap in US and European trading hours. ${ }^{2}$ Interventions that occur within 2 hours of a macro news announcement are defined as "close". ${ }^{3}$ Coordinated interventions are defined as Fed interventions that occur on the same day as at least one other of the G-3 central banks. ${ }^{4}$ The coefficient is the sum of the 36 lead and lag coefficients on each of the intervention variables. $* *, *$ denote statistical significance (of the 36 leads and lags) at the $1 \%$, and $5 \%$ levels, respectively, using robust standard errors. 
Table 8 Influence of Interventions on Intra-Day yen-usd Volatility

$$
V_{t, n}=\alpha_{0}+\sum_{k} \sum_{i} \alpha_{1, i}^{k} D_{t, n+i}^{k}+\alpha_{2} \hat{s}_{t, n}+\varepsilon_{t, n}
$$

where $\mathrm{V}$ is 5-min yen-usd volatility; $\mathrm{D}^{\mathrm{k}} \mathrm{s}$ include intervention, official central bank announcements and macro announcements; $\mathrm{i}=-1$ to $+2 \mathrm{hrs}$ for the $\mathrm{G}-3$ intervention variables and official announcements and $i=0$ to $+1 \mathrm{hr}$ for the macro announcements; $\mathrm{t}, \mathrm{n}$ is the sequence of the regular-spaced (every 5 minutes) intra-daily data for all the days on which the Fed intervened against the yen from 1989 to 1995 (66 days and a total of 192 reports of Fed operations). The reported coefficients are multiplied by 100 .

\begin{tabular}{|l|l|l|l|l|}
\hline & $\begin{array}{l}\text { Do All G-3 } \\
\text { Interventions } \\
\text { Matter? }\end{array}$ & $\begin{array}{l}\text { Does Trade } \\
\text { Volume } \\
\text { Matter? }\end{array}$ & $\begin{array}{l}\text { Does } \\
\text { Proximity to } \\
\text { Macro News } \\
\text { Matter? }\end{array}$ & $\begin{array}{l}\text { Does } \\
\text { Coordination } \\
\text { Matter? }\end{array}$ \\
\hline Independent Variable & Sum coeff & Sum coeff & Sum coeff & Sum coeff \\
\hline Fed Intervention & $0.175^{* *}$ & & & na \\
\hline Buba Intervention & 0.063 & 0.058 & 0.066 & na \\
\hline BOJ Intervention & $0.121^{* *}$ & $0.121^{* *}$ & $0.123^{* *}$ & Yes \\
\hline Official Announcements & Yes & Yes & Yes & yes \\
\hline Macro Controls & Yes & Yes & Yes & \\
\hline $\begin{array}{l}\text { Fed Interventions } \\
\text { During High Trade } \\
\text { Volume }\end{array}$ & & $0.183^{* *}$ & & \\
\hline $\begin{array}{l}\text { Fed Interventions During } \\
\text { Low Trade Volume }\end{array}$ & & $0.164^{* *}$ & & \\
\hline $\begin{array}{l}\text { Fed Interventions Close } \\
\text { to Macro News }\end{array}$ & & & $0.192^{* *}$ & \\
\hline $\begin{array}{l}\text { Isolated } \\
\text { Fed Interventions }\end{array}$ & & & $0.148^{* *}$ & \\
\hline $\begin{array}{l}\text { Coordinated } \\
\text { G-3 Interventions }\end{array}$ & & & & $0.149^{* *}$ \\
\hline $\begin{array}{l}\text { Unilateral } \\
\text { Fed Interventions }\end{array}$ & & & & $0.271^{*}$ \\
\hline FFF Seasonal & $0.168^{* *}$ & $0.166^{* *}$ & $0.168^{* *}$ & $0.164^{* *}$ \\
\hline R2 & 0.188 & 0.188 & 0.188 & 0.189 \\
\hline D.W. & 2.00 & 2.00 & 2.00 & 2.00 \\
\hline
\end{tabular}

Number of observations $=18,969 .{ }^{1}$ High trade volume is defined as the overlap in US and European trading hours. ${ }^{2}$ Interventions that occur within 2 hours of a macro news announcement are defined as "close". ${ }^{3}$ Coordinated interventions are defined as Fed interventions that occur on the same day as at least one other of the G-3 central banks. ${ }^{4}$ The coefficient is the sum of the 36 lead and lag coefficients on each of the intervention variables. $* *$, and $*$ denote statistical significance (of the 36 leads and lags) at the $1 \%$ and $5 \%$ levels, respectively, using robust standard errors. 
Table 9 Summary Statistics for Daily dem- usd and yen-usd Log Realized Volatility on Intervention and Non-Intervention Days (1989-1995)

I. Full Sample ${ }^{\mathrm{a}}$

\begin{tabular}{|l|c|c|c|c|c|c|c|c|c|c|}
\hline & Mean & $\begin{array}{c}\text { Std- } \\
\text { dev }\end{array}$ & max & min & $\begin{array}{c}\text { Skew- } \\
\text { ness }\end{array}$ & $\begin{array}{c}\text { Kurt- } \\
\text { osis }\end{array}$ & $\mathrm{Q}(20)$ & $\mathrm{d}$ & $\mathrm{AR}$ & Obs \\
\hline Dem-usd & -2.224 & 0.425 & -0.967 & -5.776 & -2.565 & 20.336 & 1811.0 & 0.273 & 0.203 & 1564 \\
\hline Yen-usd & -2.250 & 0.396 & -0.703 & -5.133 & -1.204 & 9.137 & 3318.8 & 0.424 & 0.046 & 1564 \\
\hline
\end{tabular}

II. Non-Intervention Days ${ }^{\mathrm{a}}$

\begin{tabular}{|l|l|l|l|l|l|l|l|l|l|l|}
\hline Dem-usd & -2.234 & 0.425 & -0.967 & -5.776 & -2.727 & 21.254 & 1644.2 & 0.267 & 0.204 & 1477 \\
\hline Yen-usd & -2.288 & 0.392 & -1.075 & -5.133 & -1.475 & 10.624 & 2378.9 & 0.413 & 0.059 & 1313 \\
\hline
\end{tabular}

III. All Intervention Days ${ }^{b}$

\begin{tabular}{|l|c|c|c|c|c|r|r|c|c|c|}
\hline Dem-usd & -2.067 & 0.391 & -1.067 & -2.750 & 0.494 & -0.540 & 123.2 & 0.395 & na & 87 \\
\hline Yen-usd & -2.050 & 0.352 & -0.703 & -2.945 & 0.259 & 0.334 & 454.8 & 0.400 & na & 251 \\
\hline
\end{tabular}

IV. Coordinated Intervention Days ${ }^{\mathrm{c}}$

\begin{tabular}{|l|l|l|l|l|l|l|l|l|l|l|}
\hline Dem-usd & -1.935 & 0.386 & -1.169 & -2.750 & 0.025 & -0.614 & 26.6 & 0.280 & na & 33 \\
\hline Yen-usd & -2.052 & 0.423 & -1.127 & -2.945 & 0.115 & -0.666 & 72.9 & 0.477 & na & 59 \\
\hline
\end{tabular}

V. Day Before (All) Intervention Days ${ }^{\mathrm{d}}$

\begin{tabular}{|l|r|r|r|r|r|r|r|c|c|c|}
\hline Dem-usd & -2.100 & 0.365 & -1.261 & -2.703 & 0.470 & -0.726 & 17.1 & na & na & 44 \\
\hline Yen-usd & -2.204 & 0.346 & -1.075 & -2.891 & 0.819 & 1.193 & 58.7 & 0.331 & na & 84 \\
\hline
\end{tabular}

VI. Day After (All) Intervention Days ${ }^{\mathrm{d}}$

\begin{tabular}{|l|r|r|r|r|r|r|r|c|c|c|}
\hline Dem-usd & -2.176 & 0.337 & -1.284 & -3.056 & -0.014 & 0.617 & 29.2 & na & na & 44 \\
\hline Yen-usd & -2.271 & 0.441 & -1.075 & -4.920 & -2.085 & 15.220 & 35.7 & 0.323 & na & 84 \\
\hline
\end{tabular}

Notes: The sample covers the period August 15, 1989 through August 15, 1995. The daily realized volatilities are constructed from sums of 5-minute squared returns, and are expressed as annualized standard deviations. The statistics refer to the distribution of logarithmic realized standard deviations. The column labeled $\mathrm{Q}(20)$ contains Ljung-Box test statistics for up to the twentieth order serial correlation. The column labeled "d" gives the regression estimate of the fractional integration parameter, $d$, from an $\operatorname{ARFIMA}(1, \mathrm{~d}, 0)$ model. The column labeled "AR" is the regression estimate of the autoregressive parameter from the ARFIMA $(1, \mathrm{~d}, 0)$ model.

${ }^{a}$ Five observations in the dem-usd realized volatility series were significant outliers and are excluded from the full and non-intervention samples. Realized volatility on September 14, 1992 is two times higher than the second highest day and realized volatilities on September 3-4, 1991and May 12-13, 1994 are three times smaller than the next lowest day. We replaced these outliers with values from the next highest (or lowest) realized volatilities in the sample distribution. There were no apparent outliers in the yen-usd realized volatility series.

b "All" intervention days include days of unilateral and coordinated Fed, Bundesbank and BOJ intervention operations.

${ }^{c}$ Coordinated intervention days are defined as days when the Fed intervened with either the Bundesbank or the BOJ (or both).

${ }^{d}$ The number of days before and after an intervention excludes intervention days that follow or precede other intervention days. 
Table 10 Influence of Interventions on Realized Daily dem- usd and yen-usd Volatility

$$
\begin{aligned}
& (1-L)^{d}(1-\phi L)\left(v_{t}-\mu_{t}\right)=\varepsilon_{t}, \\
& \mu_{t}=\alpha_{0}+\alpha_{1}^{k} D_{t}^{k}+\alpha_{2} H_{t} \\
& \varepsilon_{t} \sim N(0, \omega)
\end{aligned}
$$

where $v_{t}$ is the log of the sum of intra-day squared 5-minute returns (through 22GMT) excluding weekends, $H_{t}$ is a dummy variable indicating the day after a holiday or market closure and the $D^{k}$ s are dummy variables that denote daily unilateral and coordinated intervention operations.

\begin{tabular}{|c|c|c|c|c|}
\hline Independent Variables & \multicolumn{2}{|c|}{ DEM-USD } & \multicolumn{2}{c|}{ Yen-USD } \\
\hline ARFIMA parameters & Coeff & t-stat & Coeff & t-stat \\
\hline$\alpha_{0}$ & $-2.257^{* *}$ & -37.452 & $-2.374^{* *}$ & -18.122 \\
\hline $\mathrm{D}$ & $0.270^{*}$ & 5.951 & $0.455^{* *}$ & 7.019 \\
\hline$\phi$ & $0.223^{*}$ & 2.325 & & \\
\hline$\omega$ & $0.119^{*}$ & 7.052 & $0.083^{* *}$ & 8.470 \\
\hline Holiday dummy & 0.083 & 1.507 & 0.006 & 0.134 \\
\hline Fed Unilateral Intervention & $0.148^{*}$ & 2.245 & 0.354 & 1.379 \\
\hline Lag t-1 & -0.030 & -0.543 & 0.216 & 1.601 \\
\hline Lag t-2 & -0.025 & -0.448 & 0.139 & 0.978 \\
\hline Lag t-3 & -0.033 & -0.575 & $0.197 \dagger$ & 1.811 \\
\hline Lag t-4 & 0.083 & 1.442 & 0.223 & 1.250 \\
\hline Lag t-5 & 0.100 & 1.522 & -0.034 & -0.329 \\
\hline Fed Coordinated Intervention & $0.296^{* *}$ & 4.487 & $0.317 * *$ & 5.951 \\
\hline Lag t-1 & -0.030 & -0.543 & 0.042 & 0.902 \\
\hline Lag t-2 & -0.025 & -0.448 & 0.004 & 0.098 \\
\hline Lag t-3 & -0.033 & -0.575 & 0.045 & 0.882 \\
\hline Lag t-4 & 0.083 & 1.442 & 0.046 & 0.967 \\
\hline Lag t-5 & 0.100 & 1.522 & -0.033 & -0.687 \\
\hline Buba/ BOJ Unilateral Intervention & $0.152 \dagger$ & 1.885 & $0.083^{* *}$ & 8.470 \\
\hline Log Likelihood & -552.749 & -276.532 \\
\hline No of daily observations & \multicolumn{2}{|c|}{1564} & & 1564 \\
\hline
\end{tabular}

Note: An ARFIMA $(1, \mathrm{~d}, 0)$ was used to model dem- usd integrated volatility and an ARFIMA $(0, d, 0)$ was used to model yen-usd integrated volatility. Results for the variables of interest (the $D^{k} s$ ) were robust to alternative ARFIMA specifications. **, * and $\dagger$ denote statistical significance at the $1 \%, 5 \%$ and $10 \%$ levels, respectively, using robust standard errors. 
Table 11 Influence of Shocks on Realized Volatility on Non-Intervention and Intervention Days

$$
\begin{aligned}
& v_{t}=\alpha_{0}^{n}+v_{t}^{n}+v_{t}^{I}+\alpha_{2} D_{t}^{I}+\alpha_{3} H_{t}+\varepsilon_{t} \\
& v_{t}^{n}=\alpha_{1}^{n}\left(1-D_{t-1}^{I}\right) \varepsilon_{t-1}+\beta^{n} v_{t-1}^{n} \\
& v_{t}^{I}=D_{t-1}^{I}\left(\alpha_{0}^{I}+\alpha_{1}^{I} \varepsilon_{t-1}\right)+\beta^{I} v_{t-1}^{I} \\
& \varepsilon_{t} \sim N(0, \omega)
\end{aligned}
$$

where $v_{t}^{n}$ and $v_{t}^{I}$ are the log of the sum of intra-day squared 5-minute returns (through 22GMT) excluding weekends on non-intervention and intervention days, respectively. $H_{t}$ is a dummy variable indicating the day after a holiday or market closure and the $D^{I}$ is a dummy variable that denotes $\mathrm{G} 3$ intervention operations.

\begin{tabular}{|c|c|c|c|c|}
\hline & \multicolumn{2}{|c|}{ DEM-USD } & \multicolumn{2}{c|}{ Yen-USD } \\
\hline Parameter & Coeff & t-stat & Coeff & t-stat \\
\hline$\alpha_{0}^{n}$ & -2.240 & $-89.848^{* *}$ & -2.311 & $-60.965^{* *}$ \\
\hline$\alpha_{0}^{I}$ & 0.012 & 0.239 & 0.030 & 1.615 \\
\hline$\alpha_{1}^{n}$ & 0.513 & $4.244^{* *}$ & 0.451 & $5.346^{* *}$ \\
\hline$\alpha_{1}^{I}$ & 0.647 & $2.364^{*}$ & 0.479 & $6.706^{* *}$ \\
\hline$\alpha_{2}$ & 0.203 & $3.857^{* *}$ & 0.204 & $7.536^{* *}$ \\
\hline$\alpha_{3}$ & 0.081 & 1.258 & 0.005 & 0.131 \\
\hline$\beta^{n}$ & 0.633 & $4.236^{* *}$ & 0.849 & $11.306^{* *}$ \\
\hline$\beta^{I}$ & 0.736 & $10.775^{* *}$ & 0.838 & $5.703 * *$ \\
\hline$\omega$ & 0.123 & $7.418^{* *}$ & 0.085 & $9.599^{* *}$ \\
\hline Log Likelihood & \multicolumn{3}{|c|}{2.376 .48} & \multicolumn{2}{c|}{4.303 .319} \\
\hline Likelihood Ratio Statistic & \multicolumn{3}{|c|}{} \\
\hline
\end{tabular}

Note: $* *$ and $*$ denote statistical significance at the $1 \%$ and $5 \%$ levels, respectively, using robust standard errors. The likelihood ratio statistics suggest that we cannot reject the hypothesis that $\alpha_{0}^{I}=0, \alpha_{1}^{n}=\alpha_{1}^{I}$ and $\beta^{n}=\beta^{I}$, or in other words, that the persistence of shocks on intervention and non-intervention days is not statistically different. The $\beta^{I}$ estimates sugge st that the effects of shocks on intervention days fall by half in 1.5 days for dem-usd and 3 days for yen- usd. 
Figure 1

Dem-USD Exchange Rate and Central Bank Intervention, August 1989-1995

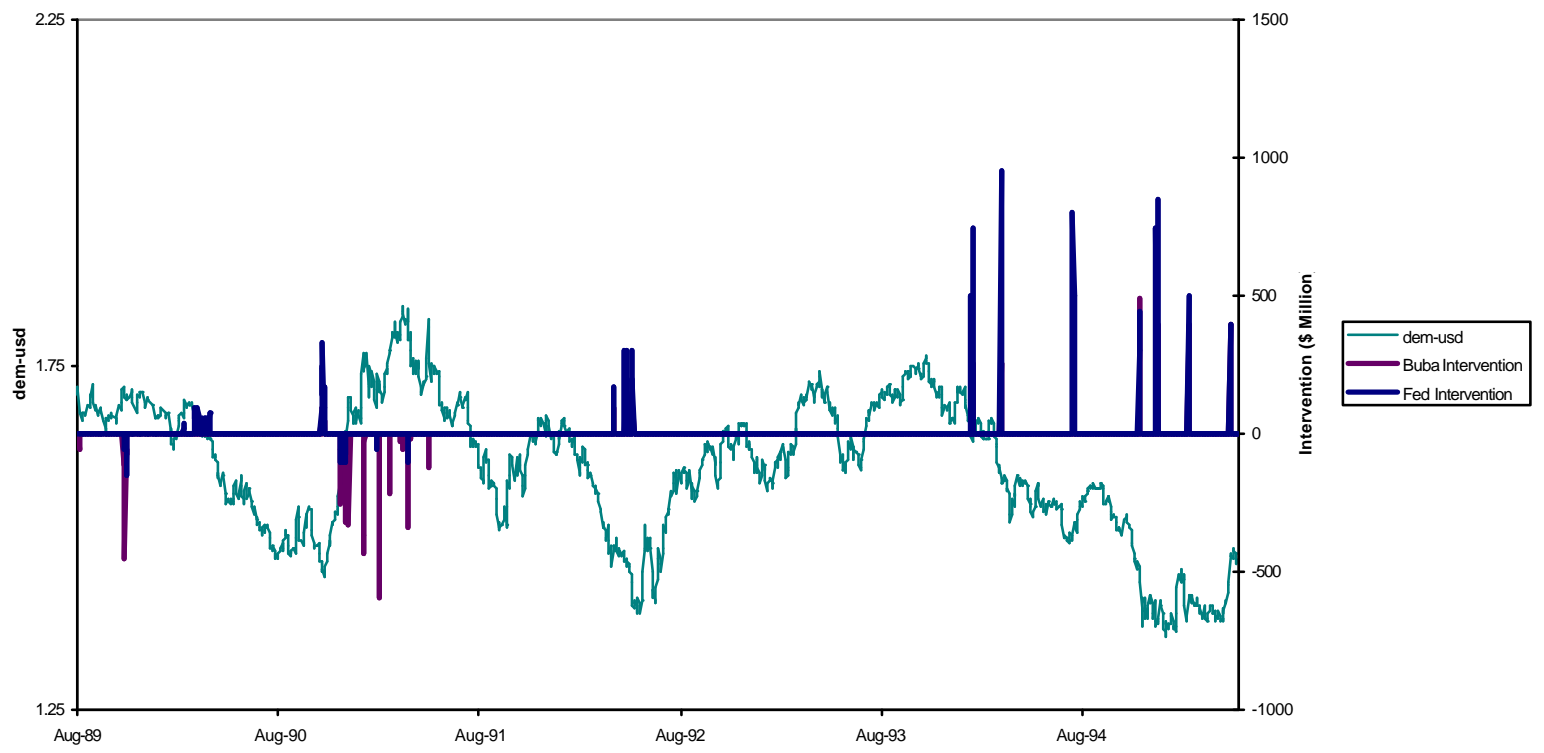

Figure 2

Yen-USD Exchange Rate and Central Bank Intervention, August 1989-1995

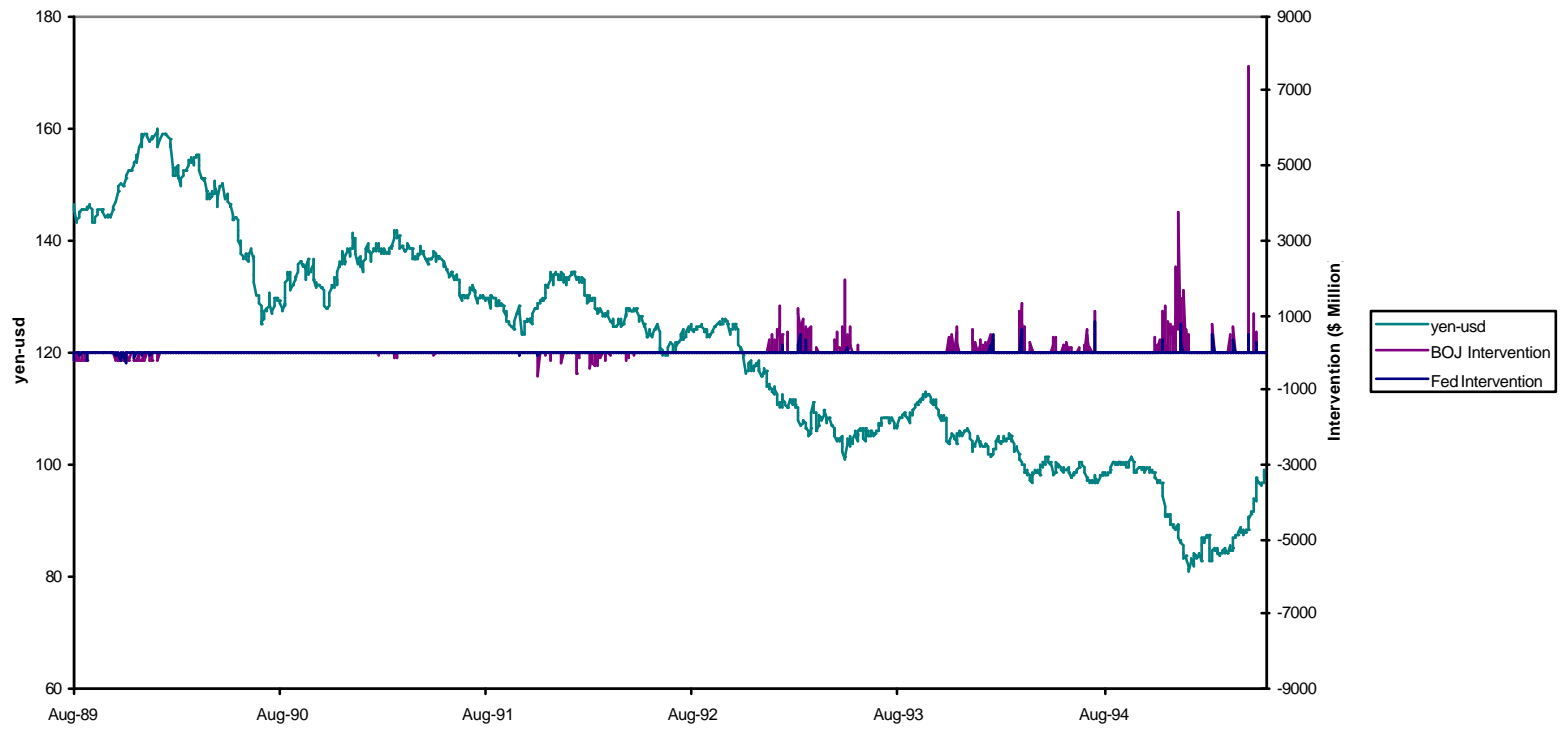


Figure 3

Dem-USD Intra-day Volatility

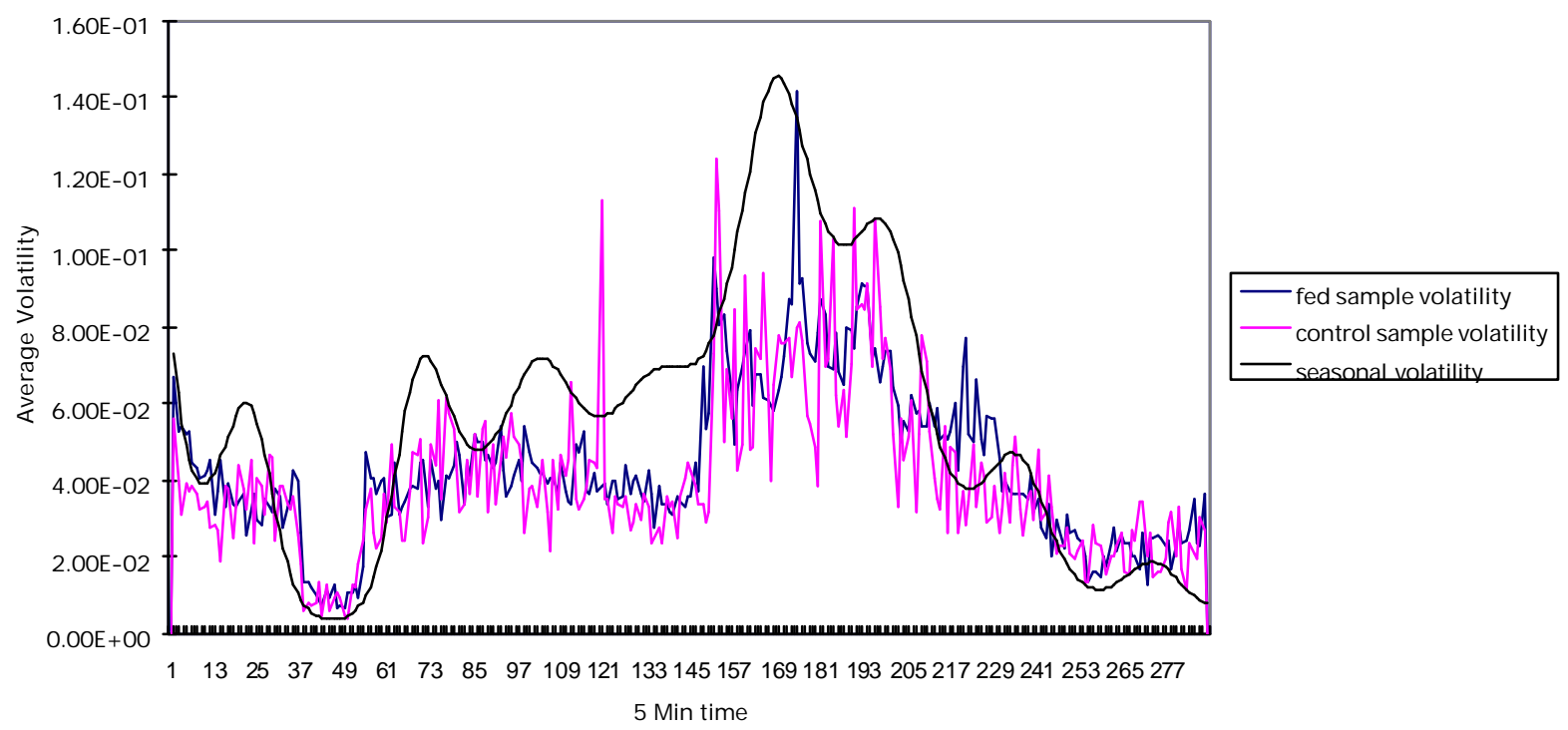

Figure 4

Yen-USD Intra-Day Volatility

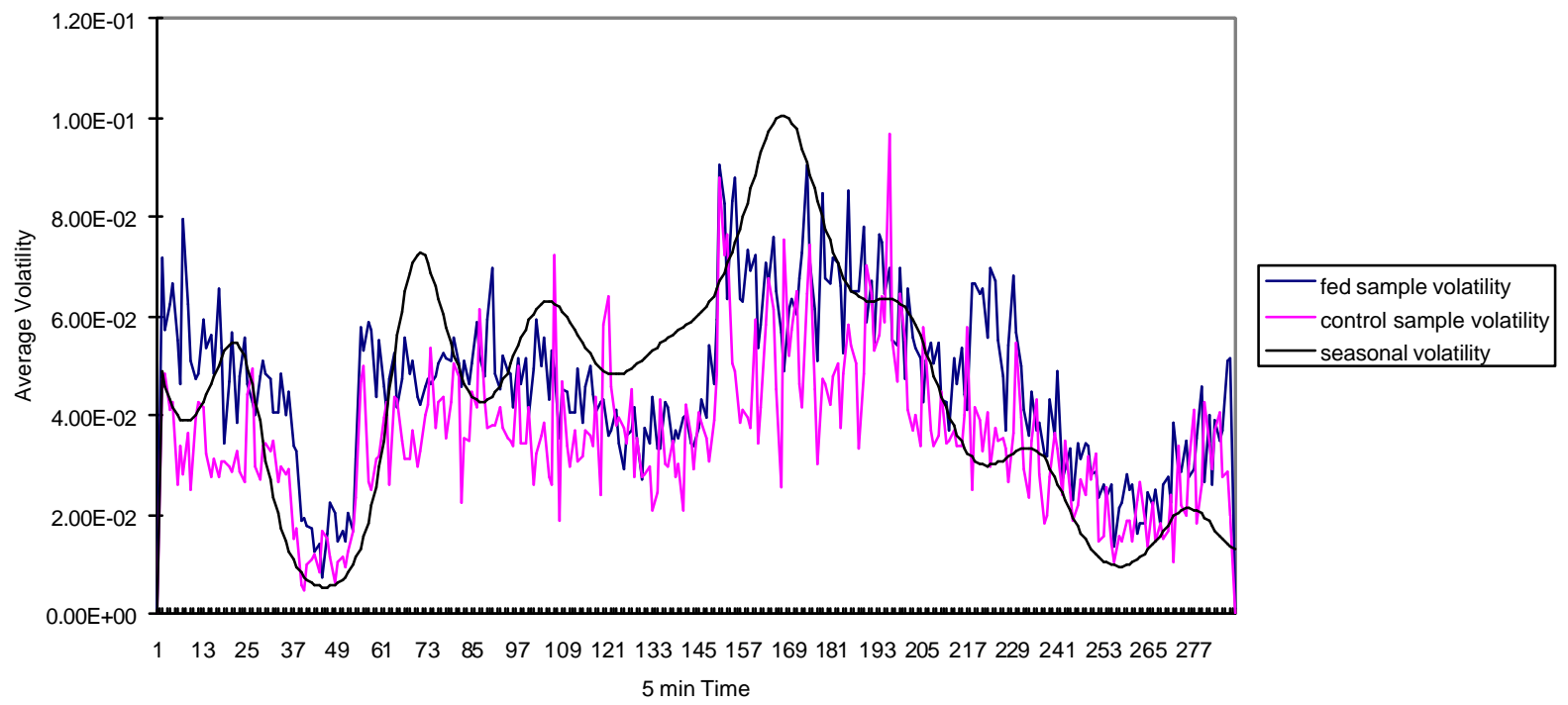


Figure 5

DEM-USD Daily Realized Volatility and MA(1)-GARCH(1,1) Volatility

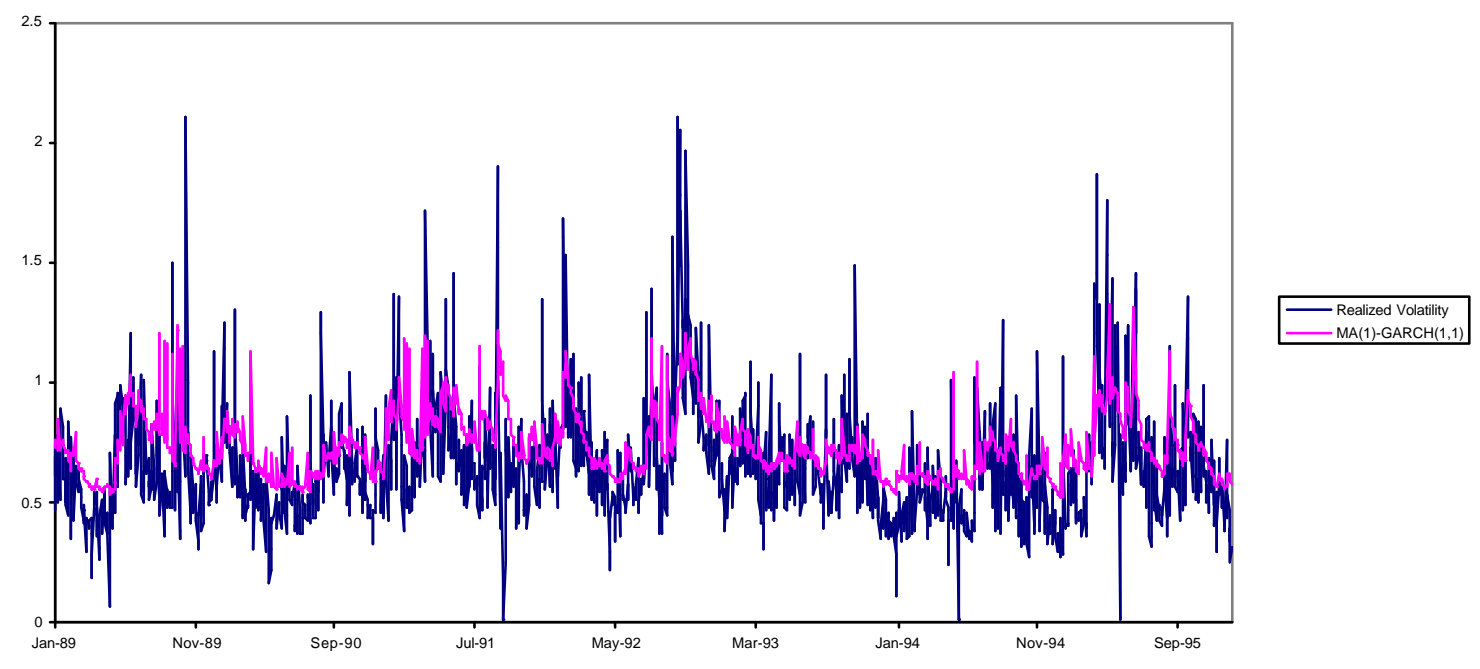

Figure 6

YEN-USD Daily Realized Volatility and MA(1)-GARCH(1,1) Volatility

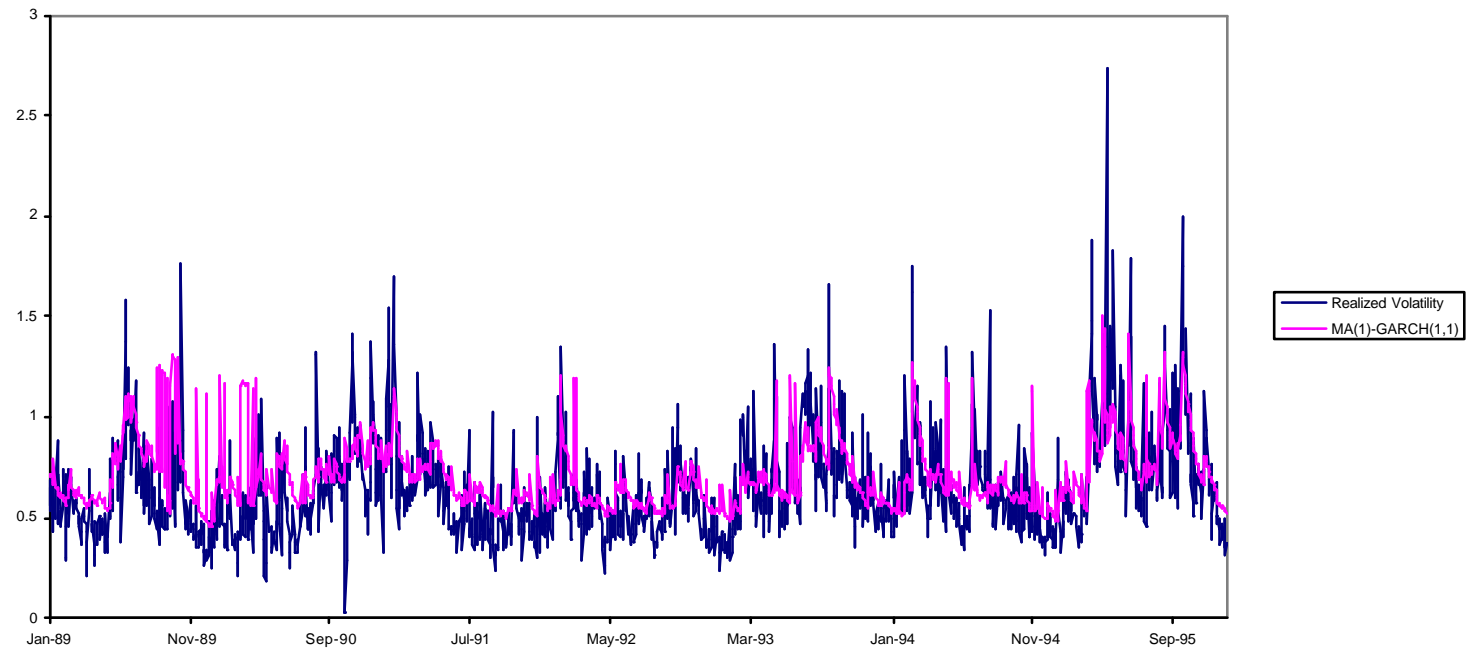

